\title{
Boson competition lifts prospects for LHC
}

Keele. William Waldegrave, Britain's minister for science, said last week that reading the successful entries in a competition to describe the significance of the Higgs boson had increased his enthusiasm for the construction of the Large Hadron Collider (LHC) being planned for the European Laboratory for Particle Physics (CERN) in Geneva specifically to search for the particle.

His expression of support comes at a time when Britain's particle physicists are preparing to tighten their belts even further in order to pay for their participation in the experimental programme on the LHC. Even so, they are warning that paying for the construction programme within current budget limits - and without, for example, participation by the United States - could lead to the suspension of all experimental work on other colliders for the five years before the LHC's planned opening in 2001.

Waldegrave was speaking during the annual meeting of the British Association for the Advancement of Science at a ceremony to award prizes for the competition which he had launched earlier this year. At a conference of the Institute of Physics, he had offered a bottle of vintage champagne - paid for, he emphasized, out of his own pocket - for the best explanation of the nature and significance of the Higgs boson written on a single side of A4 paper.

In all, 117 entries were received. And in the event, five winners were selected. Three are individual British physicists: Roger Cashmore of the University of Oxford (and chairman of the particle physics committee of the Science and Engineering Research Council), Tom Kibble of Imperial College London (widely credited for much of the theoretical argument for predicting, together with Peter Higgs, the existence of the Higgs boson); and David Miller, of University College London.

Each received a bottle of champagne as promised, as did the two other winners: a joint entry from Mary and Ian Butterworth of Imperial College, London, and Doris and Vigdor Teplitz, of the Southern Methodist University in Dallas, Texas; and Simon Hands, of CERN's theory division.

Miller's was the most imaginative answer. The others gave straightforward, if lucid, explanations of how the existence of the postulated Higgs particle would confirm the idea that particles gain mass by interacting with a field defined by certain parameters (the Higgs field). Miller chose to illustrate the idea by comparing the influence of such a field on individual particles to the clusters that would form around - and give momentum to - an "ex-prime minister" as she (sic) walked through a room of party workers, and the Higgs particles to the clusters by which a rumour would pass through the same gathering.

Commenting on the results of the competition, Waldegrave said that the entries had not only demonstrated to him why the particle was important, but had also increased his sympathy for supporters of the LHC. "If we cannot find the money - and that is going to be hard pounding - I will recognize it as a loss" he said.

Waldegrave's remarks come at a time when European governments are preparing their responses to CERN's request to be given the go-ahead for the construction of the new accelerator, which would be built in the tunnel currently occupied by the Large Electron-Positron collider (LEP).

CERN has said that it can build the new machine without any net increase in contributions from member states. Estimated to cost $£ 7$ billion (considerably less than the $\$ 11$ million for the rival Superconducting Super Collider already under construction in the United States), building work on the LHC would, if approved by the end of the year, be completed in 2001 .

But meeting Britain's CERN subscription of $£ 55$ million a year while at the same time preparing for full participation in experiments on the $\mathrm{LHC}$ is already requiring some difficult decisions by the physics community. The SERC has now endorsed a financial strategy put forward by its particle physics committee, which would achieve these objectives only by cutting back severely on planned experiments both on LEP and on Germany's electron-proton collider (HERA) at the DESY laboratory in Hamburg.

The $£ 16$ million saved in this way over the next eight years, even when added to the $£ 12$ million cut in Britain's CERN subscription negotiated last December, will not, according to the SERC panel, be sufficient to meet the total reductions needed to free funds need for the LHC. Of various options suggested, the one considered by the panel to be the most likely to succeed would be to invite contributions to the LHC from countries (in particular the United States) that are not members of CERN but make use of its facilities.

As far as Britain is concerned, says the panel, if a further reduction in its CERN contribution is not achieved, the only option will be to withdraw completely from research projects at either LEP or HERA (and perhaps even both) in 1995 or 1996. This move could leave physicists with virtually no experimental programme for the five years preceding the opening of the LHC.

\section{Stay-hard tomato carries its label with pride}

Washington. Chicago has become the first American city to pass a local law requiring that all food produced by genetic engineering must carry a label indicating this fact a worrying prospect for biotechnology companies hoping that research on plant genes will lead to the more efficient production of a swath of foodstuffs.

Chicago's move reflects a growing consumer opposition to genetically engineered The Pure Food Campaign, led by lobbyist Jeremy Rifkin, describes the Chicago law as "a devastating blow to the biotech industry", and has called on other localities to follow suit. The Campaign says that genetically engineered foods carry potential health risks, and that polls show most Americans to consider the transfer of genes from one species to another is "unethical".

New York already has a similar law in the pipeline. An attempt will be made to enact it "if the Food and Drug Administration [FDA] doesn't act soon", says a spokeswoman for the city consumer affairs department.

But the FDA itself does not appear to see any need to rush. It has just finished taking comments from interested parties on its existing policy, which requires labelling on a genetically engineered food only if the treatment has had a significant effect on the consequences of use.

And not everyone is worried about the prospect of food carrying a "genetically engineered" label. Calgene of Davis, California, whose plan to start selling its "flavour saver" tomato this autumn has caused much of the fuss, intends to put such a label on the tomato with pride, regardless of the law. The flavour saver has been produced by disabling a gene which contributes to the softening of tomatoes. It will be sold at a premium, and labelled clearly. Stephen Benoit, a spokesman for the company, says that "people have been promised a better tomato so many times before, they want to know why they should believe the promise this time".

"Calling a tomato genetically engineered tells you nothing about it at all", says Dr Eric Flamm of the FDA, who says the agency will analyse and assess the comments received in the usual way. "The Calgene tomato will be labelled at the choice of the company. There are no other products on the horizon, so I don't see any time crisis."

But the Biotechnology Industry Organisation ( $\mathrm{BIO})$ is taking seriously the threat of adverse reaction from consumers. It complains that the Chicago law was passed by council members with little consultation, and plans to work with lobby groups from the food industry to have the law repealed before it is due to take effect on 1 October.

Colin Macilwain 